\title{
PLATAFORMAS DIGITAIS DE MOBILIDADE URBANA: TIPOS E MODOS
}

DE ATUAÇÃO

TYPES OF DIGITAL PLATFORMS FOR URBAN MOBILITY

Luísa da Cunha Teixeira ${ }^{1}$, Rodrigo Cury Paraizo ${ }^{1}$

\section{RESUMO:}

Este trabalho tem como objetivo analisar o uso de plataformas digitais na mobilidade urbana. Descreve exemplos de aplicativos e plataformas agrupadas de acordo com a função que exercem sobre a mobilidade, ou seja, como elas influenciam os deslocamentos no espaço urbano. Foram catalogadas 25 plataformas em quatro categorias principais: orientação de mobilidade, transporte sob demanda, compartilhamento de veículos e compartilhamento de viagens. $\mathrm{O}$ uso da tecnologia digital revela algumas potencialidades e limitações de arranjos, usos e apropriações que merecem ser analisados com o intuito de compreender as possibilidades de ação para enfrentar os desafios que se colocam para a mobilidade urbana.

PALAVRAS-CHAVE: Mobilidade Urbana, Plataformas Digitais, Aplicativos Móveis.
Fonte de Financiamento: Conselho Nacional de Desenvolvimento Científico e Tecnológico - CNPq

Conflito de Interesse: Declara não haver.

Submetido em: 06/02/2020 Aceito em: 26/10/2020

How to cite this article:

TEIXEIRA, L. C.; PARAIZO, R. C. Plataformas digitais de mobilidade urbana: Tipos e modos de atuação. Gestão \& Tecnologia de Projetos. São Carlos, v15, n3, 2020. https://doi.org/10.11606/gtp.v15i3.166299 


\section{INTRODUÇÃO}

As redes de informação e comunicação digitais compõem parte importante da infraestrutura das grandes cidades atualmente. 0 sistema de transportes, por sua vez, se configura como outra rede fundamental ao desenvolvimento urbano. É no encontro entre essas malhas infraestruturais - informações e transportes - que se baseia este artigo.

Com o avanço das tecnologias digitais de informação e comunicação, especialmente das tecnologias baseadas em localização e a popularização dos dispositivos móveis conectados à internet, surgiram diversas plataformas e aplicativos relacionados ao transporte e mobilidade nas cidades que estão transformando a forma como são realizados os deslocamentos no espaço urbano.

Dada a natureza das próprias cidades como artefatos de concentração de ideias e recursos, além de catalisadoras de encontros, não surpreende que os aplicativos tidos como de maior impacto sobre a vida urbana sejam aqueles que interferem na mobilidade, promovendo maior eficiência nos deslocamentos.

0 debate em torno das plataformas digitais, no contexto das ditas cidades inteligentes, tem levantado diversas questões, como aquelas relativas à vigilância e controle das populações (BRUNO et al., 2018; ZUBOFF, 2015), ou as críticas à economia do compartilhamento (RÜSCHE; SANTINI, 2016; SCHOLZ, 2016; SLEE, 2017), que favorece a concentração de renda e modelos de negócios pouco regulamentados. Por outro lado, a proliferação de aplicativos móveis para smartphones possibilita a proposição de novas formas de interagir com a cidade e conectar seus habitantes e, como defendem outros autores (BEIGUELMAN, 2016; SASSEN, 2011; TOWNSEND, 2014), esses pequenos aparelhos constituem um importante dispositivo tecnológico de transformação das grandes cidades atualmente.

A qualidade da mobilidade urbana, no entanto, não é mensurada somente pela quantificação de tempos e distâncias, ainda que sejam componentes importantes, mas também e especialmente pela qualidade dos encontros - seja entre pessoas, seja de pessoas com bens, serviços ou mesmo ideias -, tanto intencionais quanto aleatórios, promovidos pelos deslocamentos. Buscaremos ressaltar também estes aspectos, visando compreender relações de interação social presentes nas novas tendências de mobilidade urbana, impulsionadas pelas redes e plataformas digitais.

Este artigo tem como objetivo analisar exemplos de plataformas digitais e aplicativos que atuam em relação à mobilidade de passageiros dentro do espaço urbano (ou seja, nos limites de uma mesma cidade ou de deslocamentos pendulares diários), organizando-os em uma categorização de acordo com suas funções no auxílio aos deslocamentos na cidade. Os exemplos foram catalogados entre junho de 2017 e dezembro de 2018, recebendo atualizações em 2019. Não são examinadas em maior profundidade alternativas que lidem com transporte de bens e serviços. Nos detemos principalmente na descrição e classificação dos exemplos, e menos em uma análise aprofundada da mobilidade urbana em si ou os desdobramentos socioeconômicos do compartilhamento e da perda da privacidade, por exemplo; no entanto, a construção de um repertório de plataformas digitais de mobilidade urbana nos possibilita analisar e comparar seus aspectos tecnológicos, sociais, econômicos e políticos, bem como sua inserção na cidade e sua relação com os produtores e usuários. Um objetivo secundário é o próprio registro de aspectos de cada um desses serviços. Dada a volatilidade de programas e plataformas, documentar agentes, históricos e aspectos funcionais contribui para a compreensão presente e futura da história social dessas tecnologias, ajudando a compreender as diferentes escolhas políticas de cada sociedade. 


\section{MOBILIDADE URBANA}

Os deslocamentos na cidade são parte fundamental da urbanidade. Por toda parte, foram sentidos os impactos de um planejamento urbano voltado ao automóvel particular, e com poucos investimentos em transporte público - contribuindo, no Brasil, para o espraiamento das cidades e a segregação urbana (VASCONCELOS, 2012). Esse modelo produziu e ainda produz diversos efeitos sobre a vida cotidiana, como o aumento do tempo dos deslocamentos, com engarrafamentos cada vez mais longos e frequentes, e o aumento da emissão de poluentes, que impactam diretamente a saúde dos habitantes, além da questão ambiental e climática (ANDRADE; LINKE, 2018).

Nos últimos dez anos, diversos autores apontam para uma mudança no modelo clássico do planejamento de transporte das cidades, quando se passa a observar a questão não mais sob o ponto de vista da oferta, mas sim da demanda (AMAR, 2016; BALASSIANO; ANDRADE; SANTOS, 2005; BANISTER, 2008; IZAGA, 2009). Esse novo paradigma adota a noção de mobilidade, trazendo maior amplitude e complexidade para a compreensão das dinâmicas dos deslocamentos urbanos, bem como a incorporação da sustentabilidade como valor fundamental.

0 conceito de mobilidade ao qual nos referimos neste artigo diz respeito aos deslocamentos físicos realizados no espaço urbano, portanto, à mobilidade dentro do espaço da cidade. Além disso, nosso recorte diz respeito à mobilidade de passageiros, deixando de lado toda a logística de transporte e distribuição de produtos e serviços.

No âmbito do planejamento de transportes, o termo mobilidade começa a ser mais utilizado com o surgimento do conceito de Gerenciamento da Mobilidade, nos EUA na década de 1980, buscando soluções e alternativas mais adequadas para a utilização do automóvel. 0 Gerenciamento da Mobilidade é considerado um "conjunto de técnicas de planejamento de transportes" (FERREIRA; BALASSIANO, 2012) que promovem meios mais sustentáveis de deslocamento de forma a tornar o sistema de transporte mais eficiente, com o objetivo de "racionalizar o uso indiscriminado do automóvel particular e estimular a utilização de formas mais sustentáveis de locomoção" (BALASSIANO; ANDRADE; SANTOS, 2005).

No Brasil, a expressão "mobilidade urbana" começa a aparecer oficialmente em 2003, com a criação da Secretaria Nacional de Transporte e da Mobilidade Urbana - SeMOB, dentro do também recém-criado Ministério das Cidades, nos primeiros anos do governo Lula da Silva. Renato Boareto (2003), então diretor de Mobilidade Urbana da SeMOB, chama a atenção para a "crise de mobilidade das cidades", causada principalmente pelo modelo de circulação centrado nos automóveis, pela ineficiência dos sistemas de transporte público e pela "abordagem fragmentada desses problemas, que dificultam sua solução". Boareto indica alguns dos desafios a serem superados no caminho para a construção de políticas públicas de mobilidade mais inclusivas e sustentáveis, definindo a Política Nacional de Mobilidade Urbana Sustentável como:

(...) o resultado de um conjunto de políticas de transporte e circulação que visa proporcionar o acesso amplo e democrático ao espaço urbano, através da priorização dos modos não-motorizados e coletivos de transporte, de forma efetiva, que não gere segregações espaciais, socialmente inclusiva e ecologicamente sustentável. Ou seja: baseado nas pessoas e não nos veículos ("Política nacional de mobilidade urbana sustentável", 2004).

A expressão se populariza ainda mais com a lei 12.587/12, sancionada em 2012, no governo Dilma Roussef, que passou a exigir que os municípios com mais de 20 mil habitantes "elaborem e apresentem um plano de mobilidade urbana, com a intenção de planejar o crescimento das cidades de forma ordenada". A Lei determina ainda que estes planos priorizem o modo de 
transporte não motorizado e os serviços de transporte público coletivo ("Política Nacional de Mobilidade Urbana", 2013).

Podemos perceber, então, que, nas últimas décadas, a mobilidade urbana se tornou um dos pontos centrais para o desenvolvimento urbano e o crescimento das cidades no mundo todo. O autor francês Georges Amar (2016) vem trabalhando com a ideia de mobilidade urbana e considera que a mobilidade é uma noção que engloba e extrapola a noção de transporte. Para ele, o transporte urbano vem sofrendo mais recentemente uma mutação de usos, ligada à inovação e à sustentabilidade, que ultrapassam a dinâmica tradicional do planejamento de transporte, e a dualidade do "transportado" e do "transportador" (AMAR, 2016, p. 37), destacando que a ideia de mobilidade pode ser cada vez mais compreendida pela criação de laços, de oportunidades e de sinergias, do que pela simples eliminação de distâncias.

O termo, portanto, acaba associado a uma visão mais ampla dos deslocamentos, para além da visão estritamente funcional, e inclui aspectos sociais e econômicos, reconhecendo de maneira mais clara também a dimensão política dos transportes. Essa mudança de entendimento, associada às próprias mudanças tecnológicas envolvendo os transportes e a comunicação, acabam fomentando novos usos e padrões de transportes, muitas vezes mediados pelas tecnologias digitais. A partir do desenvolvimento das tecnologias de localização incorporadas aos dispositivos móveis, diversas propostas vêm sendo desenvolvidas com o intuito de otimizar a mobilidade no território urbano, bem como reduzir os impactos causados nos ecossistemas local e global.

\section{A QUESTÃO DA MOBILIDADE DIGITALMENTE ASSISTIDA}

As novas tecnologias de informação e comunicação digitais vêm transformando as cidades em que vivemos de diversas formas. Dentre as práticas que agora são fortemente mediadas pelas redes digitais, uma das que mais se destaca é a mobilidade. Amar (2016) ressalta a importância da inovação, não só tecnológica, mas também cultural, com relação às novas formas e usos, para promover a mudança de paradigma do modelo clássico do planejamento de transportes em prol uma visão mais ampla, que vem se consolidando, como vimos anteriormente, na noção de mobilidade urbana. Os avanços tecnológicos vividos nas últimas décadas vêm influenciando o modo de vida do ser urbano, cada vez mais móvel e conectado, configurando o que ele chama de "vida móvel", ou seja, um modo de vida cada vez mais ligado à mobilidade (AMAR, 2016, p. 13). Para o autor, a informação, sobre todos os seus aspectos, se tornou um ingrediente essencial dos sistemas de transporte. De fato, surgem a cada dia novas ferramentas baseadas na informação para auxiliar na programação e demanda dos deslocamentos na cidade de forma mais eficiente e sustentável.

Townsend (2014, p. 57), ao conceituar "smart cities/smart urbanism", comenta o grande diferencial representado pelo advento dessas tecnologias para a capacidade de resposta e adaptação quase imediata do transporte de bens e serviços, a partir do sensoriamento remoto e processamento desses dados. Mais do que isso, há uma crescente preocupação com a dimensão humana e social intrínseca ao desenvolvimento e uso dessas tecnologias (HARTLEY, 2017; TOWNSEND, 2014). Os novos processos de inovação, privilegiando o software e a hibridização modal, estão produzindo um número cada vez maior de modos de transporte, assim como o incentivo ao compartilhamento de veículos e viagens e aos deslocamentos não motorizados. Além disso, são facilitadores importantes para uma gestão de transportes públicos melhor e mais eficiente. 


\section{PROCEDIMENTOS METODOLOGICOS}

Aplicativos móveis, ou "apps", como ficaram popularmente conhecidos, são softwares desenvolvidos para serem instalados em dispositivos eletrônicos móveis, como smartphones ou tablets, em dois sistemas operacionais principais: Android (Google) e iOS (Apple), cada qual com sua própria loja online, onde são disponibilizados os aplicativos. Em dados de novembro de 2018, a App Store, loja de aplicativos da Apple, lançada em 2008, possuía mais de 1 milhão de títulos publicados, divididos em 25 categorias que vão desde jogos a saúde e fitness. A Google Play Store, antes conhecida como Android Market, possuía 3,5 milhões de aplicações disponíveis para download, em 22 categorias.

Para o desenvolvimento desta pesquisa, realizou-se, entre junho de 2017 e dezembro de 2018, uma sistematização e classificação de diversos exemplos de plataformas digitais que atuam sobre a mobilidade urbana, com o intuito de compreender o contexto geral de aplicação das plataformas digitais nos sistemas de transporte e mobilidade urbana. A quase totalidade dessas plataformas, no momento da pesquisa, atuava principalmente a partir da interação do usuário via aplicativos móveis, ainda que possuíssem algum site para visualização em desktops. Assim, usaremos os dois termos, "plataformas" e "aplicativos", ao longo deste texto, para nos referirmos a esses programas. Em 2019, realizamos uma atualização parcial dos dados, para efeitos de publicação deste artigo.

Em um primeiro momento, nos baseamos na própria classificação dos aplicativos nas lojas online, buscando aplicativos que explicitamente falassem de transporte de passageiros e orientação no trânsito. Na App Store, verificou-se que predominavam duas categorias sobre o tema: "Viagens" e "Navegação". Já na Play Store predominavam "Mapas e navegação" e "Turismo e local"; no entanto, muitas das plataformas classificadas como "Mapas e Navegação" na Play Store eram classificadas como "Viagens" na App Store, o que dificultou estabelecer correlações entre as categorias das duas lojas. Além disso, as plataformas foram classificadas quanto ao ano de lançamento, versão do software (no Android e no iOS), data da última atualização, local de fundação, abrangência (plataformas específicas de um local, plataformas de origem local, mas replicados em outros contextos, e plataformas de aplicação geral), utilização do sinal de GPS, vínculo do condutor, propriedade do veículo, propriedade do códigofonte e função na mobilidade.

Cabe ressaltar ainda, que plataformas como o Whatsapp e o Facebook, mesmo não sendo aplicativos específicos para essa finalidade, são frequentemente usados para fins de mobilidade urbana. Seja pela própria comunicação entre os usuários combinando caronas, seja pela função de compartilhamento de localização, trata-se mais uma vez da apropriação que as pessoas fazem das tecnologias, de modo muitas vezes completamente inesperado pelos seus criadores ou empresas proprietárias. Como afirma Townsend (2014, pos. 290, tradução nossa), "se a história da construção das cidades no último século nos ensina alguma coisa, é que as consequências não intencionais das novas tecnologias frequentemente ultrapassam a intenção do projeto original".

\section{ANÁLISE DAS CATEGORIAS}

Foram catalogados durante a pesquisa 25 plataformas e aplicativos, agrupados em quatro grandes categorias: 1) orientação de mobilidade; 2) transporte sob demanda; 3) compartilhamento de veículos e 4) compartilhamento de viagens. As categorias propostas, algumas compreendendo subdivisões, classificam os exemplos de acordo com a função que exercem sobre a mobilidade urbana, ou seja, de acordo com a forma que atuam sobre os deslocamentos nas cidades. A categorização se dá especialmente a partir da perspectiva do usuário como elemento-chave da mobilidade orientada pela demanda em tempo real, seja 
mapeando rotas, seja facilitando o planejamento individual da utilização de modais diversos do sistema de transporte público.

Do mesmo modo que os problemas de mobilidade antecedem a tecnologia digital, boa parte de suas soluções também não surgiu com os smartphones. Com isso, muitas vezes, o que temos é uma ampliação de sistemas pré-existentes; mas, na escala e resposta imediata permitida pela tecnologia, essas soluções são significativamente ampliadas, a ponto de se tornarem qualitativamente distintas.

Apresentamos a seguir, a análise das categorias propostas, a partir dos exemplos encontrados. A tabela abaixo (fig.1) relaciona os exemplos analisados de acordo com a categoria em que se encaixam e com seu ano de lançamento. No exame um pouco mais detalhado, veremos características importantes para o entendimento da mobilidade urbana digitalmente assistida.

Figura 1: Tabela com exemplos organizados por categoria e ano de lançamento.

FonTE: Autores, 2019

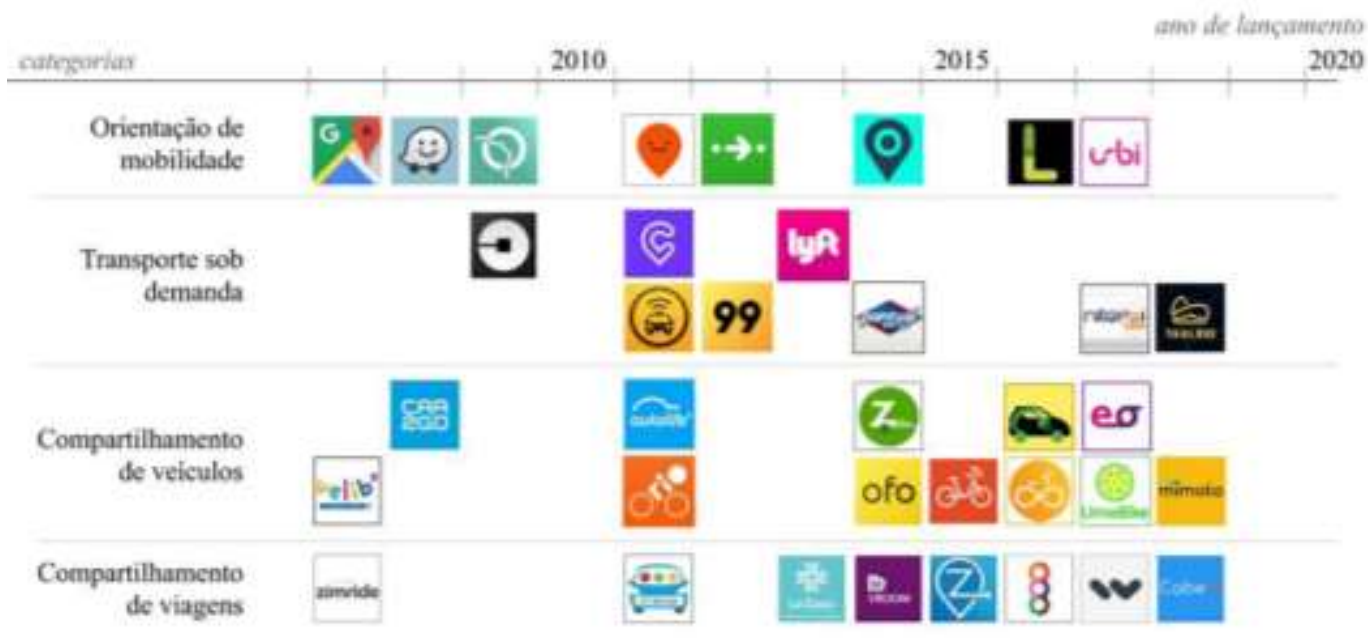

\section{ORIENTAÇÃO DE MOBILIDADE}

Essa categoria agrupa plataformas e aplicativos que atuam no auxílio à orientação para os deslocamentos na cidade. São usadas indistintamente, portanto, por motoristas a serviço de outros ou pelos próprios indivíduos em deslocamento. Os exemplos mais conhecidos são o Google Maps e o Waze Mobile, ambos presentes em vários países. Como se baseiam no sinal de GPS, que tem abrangência mundial, aplicativos desse tipo são frequentemente escalonáveis para corresponder a essa abrangência, dependendo apenas do efetivo mapeamento de ruas. Portanto, ainda que possam ter origem local, se tornam de abrangência internacional rapidamente.

A empresa Waze, originalmente LinQmap, foi fundada em 2008 em Israel, e em 2011 já empregava 80 pessoas. Seu diferencial, se comparada aos sistemas de navegação por GPS tradicionais, vem do fato de ser a primeira plataforma a se basear em informações fornecidas em tempo real por uma comunidade de usuários, aproveitando-se da localização fornecida por cada usuário através de seus smartphones e das informações ativamente enviadas sobre o tráfego, como acidentes ou presença de radares, para alimentar seu banco de dados.

Em 2013, a Waze foi comprada pela Google, e seus dados passaram a integrar um banco ainda maior, com os dados fornecidos pelo aplicativo Google Maps. Criado em 2005, o Google Maps era inicialmente uma plataforma web de mapeamento e navegação em geral, em conjunto com a Google Earth, que fornece as imagens de satélite. O serviço se baseia na pesquisa e visualização de mapas, com traçado de rotas e informações cartográficas que foram ficando cada vez mais precisas; atualmente, são fornecidos mapas de mais de 220 países, e informações 
de transporte público de mais de 15.000 cidades. Com o surgimento dos smartphones com função GPS, foi lançado, em 2008, a versão móvel do Google Maps para Android. A plataforma passou a ser alimentada também das informações de localização de seus usuários, como o Waze. 0 Google Maps, além do mapeamento, prevê o auxílio ao deslocamento usando outros modais. É possível, por exemplo, traçar uma rota a pé, ou de bicicleta, ou inclusive de transporte público, pois ele integra dados das empresas de transportes das principais cidades onde atua.

Daí inferimos outra categoria de classificação importante, do ponto de vista da mobilidade urbana: aplicativos uni ou multimodais. 0 Waze, desse ponto de vista, por ser uni-modal - e o modal em questão ser o carro particular - pode melhorar as escolhas de trajetos dos motoristas, aliviando o tráfego; o Google Maps, ao permitir a visualização de diferentes tempos de deslocamento segundo cada modal (de carro, de ônibus, a pé, de bicicleta ou mesmo de avião, quando o trajeto permite), estimula a exploração dos diferentes modais, o que pode acabar levando a escolhas mais sustentáveis, em especial para deslocamentos menores.

Um exemplo com grande eficiência na combinação de modais é a plataforma da RATP (Régie Autonome des Transports Parisiens), empresa de transporte público de Paris. Baseado nos horários de partida e/ou chegada do usuário, o aplicativo calcula a rota mais rápida, podendose escolher pelos modais a serem utilizados, trajeto mais curto, com menos trocas de transportes, entre outras opções. A plataforma integra os sistemas de metrô, ônibus, trens intermunicipais, VLT, e bicicletas públicas compartilhadas (Velib'), o que resulta em uma grande variedade de combinações possíveis para cada trajeto. 0 sistema de informações oferecido no aplicativo reflete a grande integração do sistema de transporte de Paris, que se deve, em grande parte, ao fato da RATP ser a empresa pública gestora de todos os transportes públicos na região metropolitana parisiense. Isso possibilita, além da eficiência do sistema de transporte público em si, eliminar boa parte da mediação necessária para compatibilizar os dados de diferentes sistemas.

Quando isso não é possível, as plataformas dependem das prefeituras ou órgãos gestores e empresas de transporte de cada cidade para conseguir coletar os dados, o que pode prejudicar a eficiência e confiabilidade das informações. É o caso de aplicativos como o Moovit, que pretendem ser grandes sistemas integradores de informação de transportes para quaisquer cidades. 0 Moovit é o maior aplicativo de transporte público do mundo, com mais de 150 milhões de usuários em 2200 cidades de 80 países. Na cidade do Rio de Janeiro, por exemplo, a plataforma oferece um sistema de informações de diversos modais do transporte público a partir de dados de GPS repassados pelas empresas concessionárias; no entanto, sua usabilidade é bastante questionada pela população carioca, que aponta a falta de precisão dos itinerários.

Visando oferecer um sistema mais confiável, a própria Fetranspor lançou, em 2014, o aplicativo Vá de Ônibus (que já existia como plataforma web desde 2007), que oferece a possibilidade de pesquisar as rotas e horários, além de fornecer a localização, via GPS, de todas as linhas de ônibus municipais de seu banco de dados. Mesmo assim, o sistema é ainda pouco preciso com relação à localização dos ônibus em tempo real, além de não apresentar integração com outros modais.

Da mesma forma que o aplicativo RATP reflete a eficiência do sistema de transporte público de Paris, parte das falhas da Moovit ou do Vá de Ônibus pode ser atribuída à pouca integração do sistema de transportes como um todo e também às falhas das próprias empresas no controle e monitoramento dos horários e rotas dos diferentes modais da cidade. A dificuldade em compatibilizar diferentes estruturas de dados, latências no envio das informações, e políticas de disponibilização e dos dados entre as diferentes empresas, para citarmos apenas algumas das questões envolvidas, levam a que cada empresa gestora tenha sua própria plataforma (Vá de Ônibus, Metrô Rio, Trens da Supervia, Bike Rio, etc), a ser acessada separadamente pelo 
usuário, e são uma evidência importante da influência das questões sociais e políticas, por exemplo, na adoção e evolução das proposições tecnológicas.

Essas dificuldades vêm tentando ser superadas no Brasil. Em São Paulo, por exemplo, foi lançado em 2016, o Leve-me, aplicativo de mobilidade urbana para locomoção na cidade de São Paulo (www.leve-me.com.br). A plataforma foi desenvolvida pela Ótima, Concessionária de Exploração de Mobiliário Urbano de São Paulo, e permite ao usuário escolher o destino e visualizar as melhores opções de rotas seja de ônibus, metrô, trem, bicicleta ou táxi, podendo optar pela mais rápida, confortável ou saudável. Além das opções de rota, o usuário pode interagir via realidade aumentada com campanhas publicitárias veiculadas nos painéis de pontos de ônibus. Conta também com recursos de gamificação, similares aos do Waze: neste, o usuário acumula pontos para customizar seu avatar e competir em um ranking com seus amigos do Facebook que também usam o aplicativo.

Em 2017, acompanhando ainda mais as novas tendências de mobilidade urbana foi lançado, em Berlim, o aplicativo Urbi, que integra diversas opções de mobilidade. A plataforma busca integrar os serviços de mobilidade compartilhada (bicicletas, carros e motos) e os serviços de transporte sob demanda (táxis e motorista particular), além dos modais de transporte público (https://www.urbi.co/).

Podemos perceber que os diversos aplicativos de orientação de mobilidade se atualizam para incluir novos modais e novas formas de deslocamento de seus usuários na cidade. Como mostra o exemplo da integração de transportes, mais do que uma "cidade inteligente" abstrata, é preciso que haja uma política de mobilidade urbana inteligente, presente no próprio planejamento e gestão do transporte urbano, contando com a anuência e apoio dos criadores, dos proprietários e dos mantenedores dos diferentes sistemas.

\section{TRANSPORTE SOB DEMANDA}

Em inglês, a palavra hail denomina o ato de se chamar um táxi fazendo um sinal; no recente contexto das tecnologias digitais emergentes, e-hailing denomina o "processo de chamada de um serviço de transporte individual como táxis, carros particulares ou outros veículos, por meio de um dispositivo móvel ou computador" (GONÇALVES, 2016). Os serviços de transporte sob demanda conectam de forma direta, e em tempo real, passageiros e motoristas; as empresas funcionam como plataformas mediadoras, que otimizam a comunicação entre passageiros e prestadores de serviços.

A empresa Uber é uma das maiores e mais conhecidas empresas nessa área; tão inovadora quanto polêmica, foi também a primeira empresa do tipo a oferecer seus serviços no Brasil, em 2014. Fundada em 2009, em São Francisco, EUA, sua proposta inicial era o oferecimento de um serviço de táxis de luxo, com veículos especialmente selecionados. A plataforma expandiu-se rapidamente, passou a oferecer diversas faixas de serviço, e hoje está presente em mais de 600 cidades no mundo. Plataformas concorrentes incluem a Cabify, também presente no Brasil, e a Lyft, maior concorrente da Uber nos Estados Unidos. 0 serviço opera em uma zona ainda não muito bem definida de licenciamento - não é necessário ter uma autorização pública específica, como no caso dos táxis - e de relações trabalhistas; que levou à criação do termo "uberização" para caracterizar a situação de precariedade de direitos associada a esse tipo de trabalho (SLEE, 2017).

Em 2017, a Uber lançou a modalidade "Juntos" ("Pool” em inglês), que possibilita compartilhar o carro com outros usuários com trajetos em comum, reduzindo também o valor da corrida. Embora se aproxime da definição de compartilhamento de veículos e viagens, o serviço na verdade trata de um subtipo de transporte sob demanda, caracterizado pelo compartilhamento de viagem no qual o veículo não pertence a nenhum dos passageiros, ou seja, envolve necessariamente alguém contratado para conduzir o veículo ao destino. 
Em junho de 2017, foi criada a Buser, que leva essa modalidade de serviço a uma escala ainda maior, através do fretamento compartilhado de viagens de ônibus entre grandes cidades do país. Seu funcionamento é baseado na criação de grupos de usuários que desejam realizar o mesmo trajeto. Ao atingir um número mínimo de passageiros, um ônibus é fretado e a viagem é realizada. 0 aplicativo faz a intermediação de todo o processo de reserva e pagamento; o embarque é realizado por meio de um documento de identificação, em locais normalmente mais acessíveis do que as rodoviárias comuns. Atualmente a Buser realiza por mês cerca de duas mil viagens entre 20 cidades, nas categorias semi-leito, leito ou cama. No entanto, a plataforma vem gerando atritos com as empresas de ônibus intermunicipais, que vem tentando suspender o funcionamento do aplicativo na justiça. De fato, a lógica é inversa à das companhias de ônibus tradicionais, que são contratualmente obrigadas a manter trajetos previamente combinados (beneficiando aqueles que precisam se deslocar para destinos menos populares, por exemplo), e opera os ônibus de forma dinâmica e mais eficiente, do ponto de vista da lotação.

Reagindo ao crescimento da Uber, surgiram startups visando atuar de forma similar, voltadas para o mercado de motoristas de táxi. Algumas delas cresceram e se destacam por sua abrangência cada vez maior, como é o caso da Easy Taxi, empresa brasileira fundada em 2012 no Rio de Janeiro, presente em mais de 30 países e 420 cidades. É interessante notar que um dos conceitos originais da empresa é a priorização de mercados com problemas de mobilidade urbana e sistemas de transporte deficientes, constituindo até hoje sua estratégia de expansão, com quase todos os países onde atua sendo de economias emergentes.

Outro caso de sucesso é a 99, nascida também no Brasil, que cresceu a ponto de ser comprada por 1 bilhão de reais pelo grupo Didi Chuxing, uma das gigantes chinesas de transporte e tecnologia e grande concorrente da Uber. A grande inovação da 99 foi o fato de eventualmente passar a oferecer também o serviço de motorista particular, o "99P0P", permitindo tanto que motoristas de táxi licenciados quanto motoristas particulares se registrassem no mesmo sistema.

Podemos identificar ainda muitas outras iniciativas difusas, que atuam de forma local. Os serviços de táxi, com suas centrais telefônicas, precedem em muito as plataformas de e-hailing, e hoje chegam a possuir plataformas digitais próprias. Na verdade, muitas dessas plataformas são criadas pelas mesmas empresas de tecnologia, como a Smartsis, que desenvolveu mais de 60 aplicativos de táxi publicados na Google Play Store. Recentemente, diante da competição com o Uber, a Prefeitura do Rio de Janeiro, lançou a plataforma Táxi Rio, buscando oferecer um sistema unificado, além de mais seguro e moderno, para o serviço de táxi da cidade.

Duas questões principais emergem: a primeira é que, do ponto de vista trabalhista, há diversas questões legais criadas a partir da chegada da tecnologia, mas que não são intrínsecas a ela: é sempre possível legislar em função de mais regulação tanto das relações de trabalho quanto das taxas e impostos incidentes sobre o serviço. A segunda está ligada ao impacto relativo à mobilidade: a política de preços praticada (malgrado seu impacto sobre os motoristas profissionais), por exemplo, serve como desestímulo para a posse individual de um carro, ou, pelo menos, à sua utilização diária - o que, se não reduz o número de veículos efetivamente nas ruas (LEBLANC, 2018), ao menos tende a tornar o uso dos automóveis e as viagens em si mais eficientes.

\section{COMPARTILHAMENTO DE VEICULOS}

Esta categoria agrupa plataformas que promovem o compartilhamento de veículos como bicicletas e automóveis, dentro do limite de um determinado espaço urbano, com ou sem estações pré-definidas. 
Sistemas de bicicletas compartilhadas são atualmente muito comuns nos ambientes urbanos, e mais de 400 cidades no mundo já têm seus próprios sistemas. 0 primeiro sistema, na verdade, data da 1965, e foi criado em Amsterdam, bem antes de boa parte das inovações digitais. 0 sistema de bicicletas compartilhadas de Rennes, na França, foi o primeiro a usar a tecnologia de cartão inteligente ("smart-card"), em 1998, para possibilitar a liberação das bicicletas nas estações. Em 2001, foi inaugurado o sistema Velo'v de Lyon, no qual se baseou mais tarde o sistema Vélib', de Paris. Ambos se tornaram modelos para os chamados sistemas de terceira geração (ITDP, 2014), em que a tecnologia é usada para identificar e controlar o uso em tempo real, permitindo o monitoramento da capacidade da estação e do número de usuários ativos.

No Brasil, a primeira cidade a implementar um sistema do tipo foi o Rio de Janeiro, em 2011, com o BikeRio, expandido para outras cidades a partir de 2013. Atualmente, o Rio de Janeiro possui 2.600 bicicletas disponibilizadas em 260 estações pela cidade. Recentemente, startups chinesas e estadunidenses criaram plataformas de compartilhamento de bicicletas sem estações em seus respectivos países (em inglês, dockless bike-share systems), em que as bicicletas possuem trancas individuais destravadas por QR-code e podem ser estacionadas livremente pela cidade. A Ofo, primeira plataforma desse tipo, foi fundada em 2014, seguida pela Mobike, em 2015, ambas com sede em Pequim. A Limebike, de 2017, é a versão estadunidense, com sede na Califórnia.

O compartilhamento de automóveis (carsharing, em inglês; autopartage, em francês) permite utilizar o transporte individual de forma mais racional, usando o carro apenas quando realmente necessário, e muitas vezes como um complemento a outros transportes como a bicicleta, o ônibus e o metrô. Bem menos comuns, se comparados aos de bicicletas, eles também estão cada vez mais presentes em diversas cidades do mundo. Na mesma lógica do Velib', Paris inaugurou, 10 anos depois, o sistema de compartilhamento de carros elétricos denominado Autolib', o primeiro desse tipo a ser lançado no mundo, também baseado em estações fixas, que serviam como postos de abastecimento de energia. Com os avanços tecnológicos dos carros elétricos e dos dispositivos móveis, o serviço foi desativado em julho de 2018.

O serviço Car2Go, nascido em Ulm, na Alemanha, visa o compartilhamento de automóveis com motor a combustão tradicional. Isso libera os carros do sistema de estações pré-definidas, permitindo aos usuários estacioná-los em qualquer lugar na cidade, onde podem ser encontrados pelos próximos usuários a partir do GPS de cada carro do sistema. No Car2Go, a localização dos veículos e todo o processo de reserva, abertura da porta, ignição do motor e pagamento são feitos por meio da plataforma móvel. A Car2Go é atualmente a maior empresa de compartilhamento de carro do mundo, presente em mais de 26 cidades na Europa, América do Norte e Ásia.

Uma das grandes inovações no campo da mobilidade compartilhada é a combinação da ausência de estações pré-definidas (o chamado free-floating, em inglês, ou libre-service, em francês), e a realização de todo o processo pelo smartphone com o uso de carros elétricos, misturando as vantagens do Car2Go com as do Autolib'. É o caso da Share'nGo, startup italiana fundada em Milão em 2016, que disponibiliza carros elétricos nas regiões de Milão, Florença, Roma, entre outras; da Emov, lançada em Madrid em 2017; e da Moov'in Paris (2018), lançada pela Renault. Como os carros são híbridos, podem ser parados livremente dentro de um determinado perímetro, para serem recarregados pontualmente pela empresa.

Além do compartilhamento de bicicletas e automóveis, existem plataformas que apostam no compartilhamento de outros tipos de veículos, como motos, caso de empresas como a Mimoto (2018) e a Coup (2017), ou mesmo patinetes, um dos serviços providos pela Lime (2017). No Rio de Janeiro, o serviço de patinetes elétricos começou a ser oferecido em dezembro de 2018, pela Grin (2018), com um perímetro de atuação limitado inicialmente a alguns bairros da Zona Sul. Em 2019, seu uso cresceu, tornando-se comum e até polêmico, no que se refere à segurança e à regulamentação do sistema com relação às leis de transito. 
Há uma tendência de os sistemas atuais priorizarem o uso de veículos elétricos, seja pelo apelo da sustentabilidade, seja pelo apelo do acesso a veículos elétricos, ainda comparativamente mais caros, de forma compartilhada. Já existem, fora do Brasil, sistemas de compartilhamento de bicicletas que, além de não terem estações pré-definidas, utilizam modelos elétricos, como a plataforma francesa Oribiky (2018), que oferece as bicicletas elétricas de forma complementar às tradicionais.

Apesar dos aplicativos pertencerem a uma mesma categoria, ao se examinar possíveis efeitos, é preciso considerar o tipo de modal envolvido. No caso das bicicletas, podemos inferir um estímulo ao uso da bicicleta não apenas porque o sistema dispensa a propriedade de uma, mas porque o sistema de estações acaba permitindo uma combinação eficiente da bicicleta com trechos a pé e de metrô, liberando o usuário da necessidade de estacionar a bicicleta ou de transportá-la em trens e metrôs, o que nem sempre é simples.

No que se refere aos carros, a questão da posse envolve tanto uma indústria quanto políticas de desenvolvimento econômico que seriam bastante afetadas por uma mudança cultural dessa ordem, já que a própria estrutura do negócio se alteraria - ainda que não necessariamente com menos número de viagens ou com aproveitamento mais eficiente dos veículos, já que o compartilhamento de veículos não necessariamente significa o compartilhamento das viagens em si, como veremos adiante. De todo modo, o compartilhamento de veículos é atualmente encarado como uma das grandes tendências em direção à mobilidade sustentável. Além da ressignificação do sentido da posse, que tende a reduzir o consumo, a mobilidade compartilhada permite também maior flexibilidade, possibilitando mais combinações entre transporte público e diferentes modais de uso individual, que podem ser usados em casos mais específicos e de forma complementar.

\section{COMPARTILHAMENTO DE VIAGENS}

Essa categoria agrupa plataformas que promovem o compartilhamento de viagens, normalmente em carros particulares, promovendo uma ocupação mais eficiente. Em inglês ridesharing, ou covoiturage em francês, no Brasil o ato de compartilhar uma viagem, ocupando lugares vagos é comumente conhecido pelo termo "carona", sendo uma prática de colaboração e compartilhamento antiga, comum a diversas sociedades. Separamos a análise por viagens de longa distância, realizadas entre duas cidades de forma intermunicipal, e as de curta distância, realizadas dentro de uma cidade, de forma intraurbana.

Uma das plataformas mais conhecidas atualmente é a BlaBlaCar, que visa ao compartilhamento de viagens de longa distância, ocupando as vagas ociosas em automóveis particulares. Nascida na França, em 2004, inicialmente como uma plataforma web de viagens compartilhadas chamada covoiturage.fr, o sistema se baseava em uma página na internet onde eram anunciadas as vagas ociosas para viagens de carro entre cidades na França, e os interessados podiam buscar no site por essas vagas e reservá-las, sem nenhum custo além da divisão das despesas acordada entre o motorista e os viajantes. Plataformas do mesmo tipo existiam em outros países na Europa, como Portugal (boleias.pt), Alemanha (mitfahrgelegenheit.de), Espanha, Itália, Reino Unido, entre outros. Com o aumento do uso da plataforma na França, ela começa a se expandir para outros países, comprando as plataformas concorrentes. Em 2013, a plataforma é renomeada BlaBlaCar e continua a se expandir, inclusive para fora do continente europeu, sendo, atualmente, a maior empresa de compartilhamento de viagens de longa distância do mundo. Recentemente, implementou em seus mercados na Europa o pagamento online, através de cartão de crédito, e, com isso, passou a cobrar uma taxa sobre cada reserva, conquistando um maior rendimento. No Brasil, a plataforma Tripda, com proposta semelhante, existiu de 2014 até 2016, quando teve suas atividades descontinuadas pelo elevado custo de manutenção e falta de retorno financeiro. 
A ideia de compartilhar viagens, ocupando vagas ociosas em carros particulares, não se restringe a viagens de longa distância. Viagens de curta distância, dentro de uma mesma cidade ou região metropolitana, são um nicho ainda pouco explorado. A maior dificuldade na organização de uma plataforma como o BlaBlaCar para viagens curtas dentro da cidade é que os deslocamentos intraurbanos são relativamente mais dispersos, ou seja, dada a escala desses deslocamentos, é mais difícil definir pontos de origem e destino. Já houve no Brasil algumas tentativas de criar esse tipo de plataforma, como o Minha Carona (criada por Guilherme Pim, em 2014, no Rio de Janeiro), mas que não tiveram continuidade.

Algumas iniciativas trabalham com a noção de polo gerador de viagem (PGV), e assim conseguem organizar as caronas para um determinado ponto concentrador. Os PGVs são locais ou instituições de natureza distinta, com porte e escala capazes de atrair uma quantidade significativa de pessoas e gerar um grande número de viagens, ou seja, que concentram grande quantidade de deslocamentos pendulares (PORTUGAL; GOLDNER, 2003; REDPGV, 2010). São normalmente instituições de ensino, grandes empresas, estádios, hospitais, entre outros. É possível identificar algumas plataformas que atuam em função desses polos, como, por exemplo, o Zimride, uma das maiores plataformas de viagens compartilhadas dos Estados Unidos, criada em 2007, tendo como nicho principal os campi universitários, presente em mais de 125 campi por todo o país.

No Brasil, podemos identificar algumas iniciativas semelhantes que vêm sendo testadas nos últimos tempos. A dificuldade de acesso aos campi universitários (pela precariedade de transporte público, ou a falta de integração com a cidade), além da predominância da ótica rodoviarista na maior parte dos centros urbanos, faz com que muitas pessoas utilizem carros particulares para ir e voltar das universidades. Com isso, surge também o desejo de organizar essas viagens de forma compartilhada, facilitada, hoje, pelos avanços tecnológicos e pela disseminação das redes sociais digitais. Percebendo esse movimento, algumas iniciativas surgem na forma de plataformas digitais, inicialmente restritas à web, como o Caronetas, criado em 2011. No entanto, essas plataformas não funcionaram por muito tempo, face à popularização das plataformas para dispositivos móveis e dos serviços baseados em localização. Em 2016, foi lançado na Universidade Federal do Rio de Janeiro o aplicativo Caronaê, permitindo o compartilhamento de viagens de ida e volta dos campi. Com mais de 16.000 usuários, o sistema criado por estudantes tem código-fonte aberto para permitir sua replicação em outras instituições de ensino pelo país. Uma das suas características que o distinguem de outros sistemas de compartilhamento de viagens é que o Caronaê foi pensado para uso exclusivo pela comunidade acadêmica das universidades, usando a identidade acadêmica do usuário como filtro de segurança nas viagens.

Entre as iniciativas que promovem o compartilhamento de viagens na cidade, mas que não trabalham com a noção de "polo concentrador de viagem", atuando de forma mais dispersa, temos as plataformas Waze Carpool e Wunder, que começaram a operar no Brasil a partir de 2018. A Wunder (2016), nascida na Alemanha, oferece um sistema de caronas intraurbanas, mas não possui um controle consistente da comunidade participante, sendo aberto a toda a população da cidade - o que, num primeiro momento, traz certa desconfiança pois não resolve a questão da segurança nas viagens. De todo modo, a Wunder deixou de operar no Rio de Janeiro em meados de 2019. A Waze Carpool (2015), por sua vez, é a plataforma da Waze para compartilhamento de viagens dentro da cidade. Com relação à segurança, seu diferencial é que busca relacionar, através de um endereço eletrônico profissional, pessoas que trabalham juntas e realizam diariamente o mesmo trajeto. As duas plataformas funcionam pela combinação de rotas oferecidas e buscadas, e a conexão direta entre o motorista e os caronistas pelo aplicativo, que conta também com sinal de GPS para facilitar o encontro, como acontece no Uber ou 99. Tanto no Waze Carpool quanto no Wunder, há obrigatoriedade do pagamento da carona, através do próprio aplicativo. 
O compartilhamento de viagens, em especial no caso do automóvel, traz o benefício da utilização mais eficiente do modal (mais passageiros por carro). Vale observar, no entanto, que, ao menos no contexto universitário (e o raciocínio é facilmente extensível a outros PGVs), a redução de carros nas ruas ocorre apenas quando um proprietário de carro decide pegar uma carona (ou o transporte público), posto que os outros passageiros estão apenas buscando alternativas ao transporte público pouco eficiente. Por outro lado, ao forçar a convivência entre duas pessoas, muitas vezes desconhecidas (mas com a devida salvaguarda de segurança do cadastro no sistema), a prática pode estimular justamente o tipo de encontro casual vital para as cidades. Ou seja, o compartilhamento de viagens, mais do que o compartilhamento de veículos, pode fomentar o encontro entre pessoas na cidade, fortalecendo o contato e a colaboração entre indivíduos de uma mesma comunidade. Nesse sentido, é uma prática que incentiva uma maior participação e interação em ações coletivas.

\section{CONSIDERAÇÕES FINAIS}

Podemos perceber que há uma grande quantidade de serviços digitais oferecidos atualmente no campo da mobilidade. Desde sistemas de orientação e oferta de transporte público, que visam auxiliar o usuário a encontrar as melhores rotas, linhas de ônibus, metrô e trens, aos de transporte sob demanda, que incluem os serviços de táxi e, mais recentemente, os de motorista particular.

Muitas dessas alternativas nascem da observação de uma realidade marcada por um transporte público ineficiente, precário e custoso, e acabam por modificar a própria maneira de agir dos transportes tradicionais, mesmo quando complementam a oferta regular desses transportes. A aplicação das tecnologias de informação e comunicação na cidade vem sendo pensada por diversos atores e elas podem representar tanto interesses corporativos de grandes atores econômicos quanto alternativas inovadoras de baixo custo, feitas de forma colaborativa e "de baixo para cima". As plataformas e aplicativos aqui analisados devem ser enxergados sob essa lente, evitando um olhar descolado da realidade econômica e política da qual faz parte a dinâmica das plataformas digitais.

As questões que se colocam para a mobilidade urbana atualmente são um dos maiores problemas das grandes cidades do mundo. A busca por soluções que possibilitem ao menos mitigar os efeitos causados pelo excesso de veículos motorizados pode ser observada nos exemplos estudados, em diferentes níveis, e elas passam principalmente pela ideia do compartilhamento. Algumas das plataformas que atuam no campo da mobilidade urbana nasceram de uma associação cooperativa entre pessoas de uma comunidade, buscando solução para problemas locais, outras são fruto das pesquisas e investimentos do Vale do Silício. A coexistência de apropriações das tecnologias digitais com distintas ênfases reforça a dicotomia existente. Ao mesmo tempo que fornecem ferramentas para a conexão entre as pessoas de forma direta e horizontalizada, também permitem a criação de grandes empresas-plataforma que centralizam e exploram economicamente os serviços.

Um exemplo claro da necessidade de observar as interações sociais com a tecnologia surgiu recentemente com a pandemia de COVID-19 no Brasil e no mundo em 2020. Nesse período, podemos observar algumas mudanças significativas no uso da maioria dos exemplos aqui analisados. 0 distanciamento social impõe restrições e condições para os deslocamentos realizados na cidade, nesse sentido, fica dificultado o acontecimento de caronas, e mesmo, o transporte por taxi e carros de aplicativos, mas principalmente o transporte público coletivo. Podemos dizer que há uma diminuição do uso de aplicativos para transporte de passageiros, aqui analisados, e um aumento significativo do transporte de bens - como comida - por aplicativo, os aplicativos de entrega, que já vinham crescendo, mas ganham outra proporção e importância com o início do isolamento social. 
O discurso de valorização do compartilhamento não pode ser tomado como valor absoluto. Antes, é preciso examinar o que exatamente está sendo compartilhado, e como. Existe grande diferença entre compartilhamento de viagens e de veículos, por exemplo, em termos de emissão de poluentes ou mesmo de carros nas ruas. Por outro lado, a eficiência de compartilhamento, ligada ao conceito de gerenciamento de banco de dados das chamadas smart cities, também tem seus efeitos colaterais, na forma da perda de privacidade dos dados, algo que sempre merece ser examinado mais a fundo, sopesando o quanto devemos, ou queremos, abrir mão da privacidade individual para permitir o gerenciamento mais eficiente de informações e recursos.

\section{Agradecimentos}

Este estudo foi financiado em parte pela Coordenação de Aperfeiçoamento de Pessoal de Nível Superior - Brasil (CAPES) - Código Financeiro 001; e também pelo Conselho Nacional de Desenvolvimento Científico e Tecnológico (CNPq), que concedeu a bolsa de estudos para o Mestrado em Urbanismo do PROURB/UFRJ. Os autores agradecem aos colegas do Laboratório de Análise Urbana e Representação Digital - LAURD/PROURB pelas contribuições e ao Programa de Pós-Graduação em Urbanismo - PROURB/UFRJ pelo apoio.

\section{Referências Bibliográficas}

AMAR, G. Homo mobilis: une civilization du mouvement. Paris: FYP Editions, 2016.

ANDRADE, V.; LINKE, C. C. Cidades de pedestres: a caminhabilidade no Brasil e no mundo. Rio de Janeiro: Babilônia Cultura Editorial. , 2018

BALASSIANO, R.; ANDRADE, A. R.; SANTOS, M. P. Gerenciamento da mobilidade: princípios para a sua aplicação com base na informação. Revista Cetrama, v. 02, 2005.

BANISTER, D. The sustainable mobility paradigm. v. 15, p. 73-80, 2008.

BEIGUELMAN, G. Cidades de código aberto: arte, arquitetura e design no espaço informacional. In: ROZESTRATEN, A. S. et al. (Org.). Atas do $1^{\circ}$ Colóquio Internacional ICHT 2016 - Imaginário: construir e habitar a terra. Cidades “inteligentes" e poéticas urbanas. São Paulo: [s.n.], 2016. p. 650.

BOARETO, R. A mobilidade urbana sustentável. Revista dos Transportes Públicos - ANTP, v. 25, n. 3, 2003.

BRUNO, F. et al. (Org.). Tecnopolíticas da vigilância: perspectivas da margem. São Paulo: Boitempo, 2018.

FERREIRA, A. F.; BALASSIANO, R. Gerenciamento da mobilidade em Pólos Geradores de Tráfego: o caso das Instituições de Ensino. 2012, Joinville: ANPET - Associação Nacional de Pesquisa e Ensino em Transportes, 2012. p. 364-376.

GONÇALVES, C. L. R. As plataformas de e-hailing presentes no ecossistema de mobilidade urbana no Brasil: um estudo de múltiplos casos. 2016. Instituto COPPEAD de Administração - UFRJ, Rio de Janeiro, 2016.

HARTLEY, S. The fuzzy and the techie : why the liberal arts will rule the digital world. 1. ed. New York: Houghton Mifflin Harcourt Publishing Company, 2017.

IZAGA, F. G. DE. Mobilidade e centralidade no Rio de Janeiro. 2009. 310 f. Programa de PósGraduação em Urbanismo, Rio de Janeiro, 2009. 
Política Nacional de Mobilidade Urbana. Brasília: [s.n.], 2013. Disponível em:

$<$ http://www.portalfederativo.gov.br/noticias/destaques/municipios-devem-implantar-planoslocais-de-mobilidade-urbana/CartilhaLei12587site.pdf>. Acesso em: 29 ago. 2018.

Política nacional de mobilidade urbana sustentável. Cadernos MCidades. Brasília: Ministério das Cidades. , 2004

PORTUGAL, L. DA S.; GOLDNER, L. G. Estudo de Polos Geradores de Tráfego e de seus impactos nos sistemas viários e de transportes. 1. ed. São Paulo: Edgar Blücher, 2003.

REDPGV. O Que é um PGV. Disponível em: <http://redpgv.coppe.ufrj.br/index.php/ptBR/conceitos/o-que-e-um-pgv>. Acesso em: 13 nov. 2018.

RÜSCHE, A.; SANTINI, D. Plataformas de solidariedade. In: SCHOLZ, T. (Org.). . Cooperativismo de plataforma. São Paulo: Fundação Rosa Luxemburgo; Editora Elefante; Autonomia Literária, 2016. p. 7-14.

SASSEN, S. Open Source Urbanism. Domus, 2011. Disponível em:

<https://www.domusweb.it/en/op-ed/2011/06/29/open-source-urbanism.html>. Acesso em: 29 ago. 2018.

SCHOLZ, T. Cooperativismo de Plataforma. São Paulo: Fundação Rosa Luxemburgo; Editora Elefante; Autonomia Literária, 2016.

SLEE, T. Uberização: a nova onda do trabalho precarizado. 1. ed. São Paulo: Editora Elefante, 2017. TOWNSEND, A. M. Smart cities : big data, civic hackers, and the quest for a new utopia. Nova Iorque: W. W. Norton \& Company, 2014.

VASCONCELOS, E. A. DE. Mobilidade Urbana e Cidadania. Rio de Janeiro: SENAC, 2012.

ZUBOFF, S. Big other: Surveillance capitalism and the prospects of an information civilization. Journal of Information Technology, v. 30, n. 1, p. 75-89, 2015. Disponível em:

$<$ http://dx.doi.org/10.1057/jit.2015.5>. 